\title{
Role of erlotinib in the targeted treatment of non-small-cell lung cancer in Chinese patients
}

\author{
This article was published in the following Dove Press journal: \\ OncoTargets and Therapy \\ 13 February 2014 \\ Number of times this article has been viewed
}

Wei Li

Fei Zhou

Caicun Zhou

Shanghai Pulmonary Hospital, Cancer Institute, Tongji University School of Medicine, Shanghai, People's Republic of China
Correspondence: Caicun Zhou Shanghai Pulmonary Hospital,

Cancer Institute, Tongji University School of Medicine, 1239 Siping Road, Shanghai 200433, People's Republic of China

Tel +862I 65I I 5006 ext 3050

Email caicunzhoudr@I63.com
Abstract: Epidermal growth factor receptor (EGFR) tyrosine kinase inhibitors (TKIs) have been demonstrated to improve responses and clinical outcomes significantly in patients with advanced non-small-cell lung cancer (NSCLC). In retrospective subgroup analyses of several studies, patients with Asian ethnicity (including Chinese) are a subpopulation who responds well to EGFR TKI therapy. Since EGFR-mutation status has emerged as an important predictor of a substantially increased benefit, the high mutation rate in the Asian (including Chinese) population could be the explanation for a superior benefit from EGFR TKI therapy. Erlotinib $\left(\right.$ Tarceva $\left.^{\circledR}\right)$, one of the EGFR TKIs, has been proved to be effective in second- and third-line therapy, and furthermore in first-line and maintenance settings. In this review, we summarize current data of clinical trials with erlotinib and discuss its role in the targeted treatment of NSCLC in Chinese patients.

Keywords: NSCLC, EGFR TKI, erlotinib

\section{Introduction}

Lung cancer is the leading cause of cancer-related mortality in men and women throughout the world, including the People's Republic of China (PRC). ${ }^{1,2}$ According to the Chinese Cancer Registry Annual Report, the crude incidence rate of lung cancer was 53.57 per 100,000 in 2009 , and the incidence rate of males $(70.40$ per 100,000$)$ was 1.94 times as much as that of female (36.34 per 100,000). The mortality rate of lung cancer was 45.57 per 100,000 , and the mortality rate of male was $(61.00$ per $100,000), 1.94$ times as much as that of females $(29.77$ per 100,000$) .{ }^{1}$ In the last three decades, the morbidity and mortality rates of lung cancer in Chinese populations have increased annually and have become higher than the worldwide average, owing to growing smoking habits and environmental pollution. ${ }^{3}$

Non-small-cell lung cancer (NSCLC) comprises the most common form of lung cancer, with the majority of patients presenting with advanced disease at the time of diagnosis. ${ }^{4}$ For these patients, palliative chemotherapy with platinum-based doublets was once considered to be the only standard treatment, with limited efficacy and usually serious side effects. ${ }^{5,6}$ However, recent advances in targeted and individualized therapy have provided us with alternative approaches for the treatment of NSCLC. Epidermal growth factor receptor (EGFR) tyrosine kinase inhibitors (TKIs), the most commonly studied targeted agents, have been demonstrated to improve responses and outcomes in patients with advanced NSCLC significantly. ${ }^{7}$ Erlotinib (Tarceva ${ }^{\circledR}$; San Francisco, CA, USA), one of the oral EGFR TKIs, has been proved to be effective in secondand third-line therapy, ${ }^{8,9}$ and furthermore in first-line ${ }^{10-12}$ and maintenance settings. ${ }^{13}$ 
Therefore, erlotinib has been approved in more than 80 countries for the treatment of advanced NSCLC, and was also approved in the PRC in 2006.

In retrospective subgroup analyses of several studies, patients with Asian ethnicity are a subpopulation that responds well to EGFR TKI therapy. ${ }^{14,15}$ With further research focusing on identifying biomarkers to predict clinical benefit of EGFR TKIs, EGFR-mutation status has emerged as the strongest predictor for clinical benefit from EGFR TKI therapy. ${ }^{16,17}$ Therefore, the main reason for better outcomes in Asian patients compared with Western patients is probably the result of the higher incidence (around $30 \%-40 \%$ ) of EGFR-sensitive mutations in exon 19 and 21 in Asian patients than in Western patients. ${ }^{18-20}$ Not surprisingly, Chinese advanced NSCLC patients with a mutation rate of $49.8 \%$ obtained significant benefit from EGFR TKI treatment. $^{21}$

In this review, we summarize current data of clinical trials with erlotinib and discuss its role in the targeted treatment of NSCLC in Chinese patients.

\section{Erlotinib as second-line or later therapy}

Several clinical trials have confirmed the antitumor activity of erlotinib as second-line or later therapy in patients with advanced NSCLC (Table 1). In the BR.21 study, a randomized, double-blind, Phase III trial in 731 patients with advanced NSCLC who had received at least one line of chemotherapy, ${ }^{8}$ erlotinib significantly prolonged survival: progression-free survival (PFS) 2.2 months versus 1.8 months (hazard ratio [HR] 0.61, $P<0.001$; overall survival [OS]
6.7 months versus 4.7 months, HR 0.70, $P<0.001$ ), delayed symptom deterioration, and provided quality of life benefits compared with placebo. The subgroup analysis showed that erlotinib was associated with longer survival among women ( $P=0.006)$, lifetime nonsmokers $(P<0.001)$, Asians $(P=0.02)$, and patients with adenocarcinoma $(P<0.001)$. Based on these promising data, erlotinib was approved as standard treatment for advanced NSCLC in second- or third-line settings by the US Food and Drug Administration and the European Medicines Agency.

The Tarceva Lung Cancer Survival Treatment (TRUST) study was a large international, open-label, Phase IV study of erlotinib that was designed to investigate the efficacy of erlotinib monotherapy for patients with advanced NSCLC who had previously failed on or were considered unsuitable to receive standard chemotherapy. ${ }^{9,22}$ A total of 6,665 patients were enrolled into the study, with 1,242 patients recruited within the East/Southeast (E/SE) Asian region (including 519 patients in the PRC). To validate the hypothesis that treatment outcomes in the Asian population would be superior to the non-Asian population, further efficacy and safety data of erlotinib in E/SE Asian patients with advanced NSCLC were analysed. ${ }^{2,3}$ Compared with patients in other regions, both the overall response rate (ORR) and disease-control rate (DCR) were significantly higher in E/SE Asian patients (ORR 27\% versus $10 \%, P<0.0001$; DCR $78 \%$ versus $66 \%, P<0.0001$; respectively). The median PFS for the E/SE Asian population was 5.78 months, compared with 2.92 months for the non-E/SE Asian population and 3.25 months for the overall global population. The median OS values were 14.7, 6.8, and 7.9 months, respectively. Multivariate analyses for PFS

Table I Erlotinib versus placebo or chemotherapy in second-line setting

\begin{tabular}{|c|c|c|c|c|c|c|c|c|}
\hline Study & $\begin{array}{l}\text { Study } \\
\text { phase }\end{array}$ & Treatment & Population & ORR (\%) & $\begin{array}{l}\text { Median PFS/ } \\
\text { TTP (months) }\end{array}$ & HR PFS & $\begin{array}{l}\text { Median OS } \\
\text { (months) }\end{array}$ & HR OS \\
\hline \multirow[t]{3}{*}{ BR2I } & Phase III & Erlotinib & Overall ITT & 8.9 & 2.2 & HR $0.6 \mathrm{I}$ & 6.7 & HR 0.70 \\
\hline & & Placebo & & $<1$ & 1.8 & $P<0.00 I$ & 4.7 & $P<0.001$ \\
\hline & & & & $P<0.00$ I & & & & \\
\hline \multirow[t]{5}{*}{ TRUST } & Phase IV & Erlotinib & Overall ITT & 13 & 3.25 & & 7.9 & \\
\hline & & & E/SE Asian & 27 & 5.78 & HR 0.66 & 14.7 & HR 0.57 \\
\hline & & & Non-E/SE Asian & 10 & 2.92 & $P<0.0001$ & 6.8 & $P<0.000$ I \\
\hline & & & & $P<0.000$ I & & & & \\
\hline & & & Chinese & 26.7 & TTP $=6.44$ & & 15.37 & \\
\hline \multirow[t]{3}{*}{ DELTA } & Phase III & Erlotinib & EGFR wild-type & NP & 1.3 & & 9.0 & \\
\hline & & Docetaxel & & & 2.9 & & 9.2 & \\
\hline & & & & & $P=0.013$ & & $P=0.914$ & \\
\hline \multirow[t]{3}{*}{ CTONG0806 } & Phase II & Gefitinib & EGFR wild-type & 14.7 & 1.6 & HR 0.5 I & NA & \\
\hline & & Pemetrexed & & 13.3 & 4.8 & $P<0.001$ & & \\
\hline & & & & $P=0.814$ & & & & \\
\hline
\end{tabular}

Abbreviations: EGFR, epidermal growth factor receptor; ITT, intention to treat; ORR, objective response rate; PFS, progression-free survival;TTP, time to progression; OS, overall survival; HR, hazard ratio; E/SE, East/Southeast; NA, not available; NP, not present;TRUST,Tarceva Lung Cancer Survival Treatment; DELTA, Docetaxel and Erlotinib Lung Cancer Trial; CTONG, Chinese Thoracic Oncology Group. 
and OS showed that smoking status (nonsmoker), histology (adenocarcinoma/bronchioloalveolar carcinoma), and sex (females) were all predictive of longer survival with erlotinib, while these characteristics were considered to be potentially indicative of a high incidence of EGFR mutation. ${ }^{23}$

As a subgroup of Asian patients, 519 Chinese patients were enrolled. Of these patients, one case had complete response, 127 cases had partial response, 263 cases had stable disease, and 88 cases had progressive disease, resulting in an ORR of $26.7 \%$. The median time to progression (TTP) was 6.44 months, and median OS was 15.37 months. The major erlotinib treatment-related adverse events (AEs) were mild (Common Terminology Criteria AE grade 1/2), while only three cases had severe AEs and one case had interstitial lung disease and died of respiratory failure.

To investigate the role of erlotinib further as secondline treatment in unselected advanced NSCLC patients, the Docetaxel and Erlotinib Lung Cancer Trial (DELTA) study was conducted to compare the efficacy of erlotinib with docetaxel in patients previously treated with chemotherapy. ${ }^{24}$ The primary analyses focusing on EGFR wild-type tumors were reported at the annual meeting of the American Society of Clinical Oncology (ASCO) 2013, and revealed that patients with $E G F R$ wild-type tumors achieved significantly longer PFS in the docetaxel arm than in the erlotinib arm (median PFS 2.9 months versus 1.3 months, $P=0.013$ ), while the difference did not translate into OS (median OS 9.0 months versus 9.2 months, $P=0.914)$. Another Phase II trial, Chinese Thoracic Oncology Group (CTONG) 0806, which was also reported at the ASCO 2013 meeting, compared pemetrexed with gefitinib as second-line treatment of nonsquamous NSCLC patients with wild-type $E G F R .^{25} \mathrm{PFS}$ was 1.6 months versus 4.8 months (HR 0.51, $P<0.001$ ), ORR was $14.7 \%$ versus $13.3 \%(P=0.814)$, and DCR was $32.0 \%$ versus $61.3 \%$ $(P<0.001)$ for the gefitinib arm and pemetrexed arm, respectively. These results showed that patients with wildtype EGFR did not benefit from EGFR TKIs compared with chemotherapy in the second-line setting.

\section{First-line therapy for advanced NSCLC}

In preclinical models, the antitumor activity of erlotinib was enhanced in combination with chemotherapy. The efficacy of erlotinib in combination with chemotherapy as first-line treatment of advanced NSCLC was evaluated in two large, multicenter, randomized, placebo-controlled clinical trials: TRIBUTE (Tarceva responses in conjunction with paclitaxel and carboplatin $)^{26}$ and the Tarceva Lung Cancer Investigation (TALENT; erlotinib plus cisplatin and gemcitabine) trails. ${ }^{27}$ However, neither study demonstrated that concurrent combination of erlotinib and chemotherapy improved efficacy, and thus this drug was not recommended as first-line treatment for advanced unselected NSCLC patients. Therefore, it is necessary to identify patients who may benefit from first-line EGFR TKI therapy.

The Iressa Pan-Asia Study (IPASS), a multicenter, Phase III, randomized study to compare gefitinib with carboplatin plus paclitaxel as first-line treatment in clinically selected patients in East Asia, ${ }^{28}$ highlights that EGFR-mutant lung cancer is a distinct subgroup for EGFR TKI treatment with superior clinical outcomes. Subsequently, two Japanese trials comparing first-line gefitinib versus chemotherapy for exclusive EGFR-mutant lung cancers confirmed the conclusion of IPASS..$^{29,30}$ Therefore, the OPTIMAL (Erlotinib Versus Gemcitabine/Carboplatin in Chemo-naive Stage IIIB/IV non-Small Cell Lung Cancer Patients with Epidermal Growth Factor Receptor [EGFR] Exon 19 or 21 Mutation [ML20981]; CTONG 0802) study was initiated to compare the efficacy and tolerability of first-line erlotinib versus gemcitabine plus carboplatin (GC) in advanced or metastatic NSCLC patients harboring activating EGFR mutations in the $\mathrm{PRC}^{10}$ (Table 2). The primary end point was PFS, and secondary end points included OS, quality of life, and RR. A total of 165 patients were randomized to treatment, and 154 patients received at least one dose of the study drug. In the OPTIMAL study, erlotinib was significantly superior to chemotherapy in terms of PFS, with median PFS of 13.1 months versus 4.6 months (HR $0.16,95 \%$ confidence internal [CI] 0.10-0.26; $P<0.0001)$. The subgroup analysis showed that almost all subgroups (sex, histology, and smoking status) obtained more clinical benefits from erlotinib than from chemotherapy. The ORR was $83 \%$ (68 of 82 ) for erlotinib and 36\% (26 of 72) for chemotherapy $(P<0.0001)$. As with PFS, response to erlotinib was similar across clinical subgroups. In terms of safety, erlotinib proved to be better tolerated than chemotherapy. Erlotinib was associated with less grade 3 or 4 toxic effects than chemotherapy (including neutropenia in 30 of 72 patients and thrombocytopenia in 29 patients on chemotherapy versus no patients with either event on erlotinib); the most common grade 3 or 4 toxic effects with erlotinib were increased alanine aminotransferase concentrations $(4 \%$, three of 83$)$ and skin $\operatorname{rash}(2 \%$, two of 83$)$.

Another Phase III clinical trial, which was performed in Europe - EURopean TArceva vs Chemotherapy (EURTAC) - also showed that when compared with 
Table 2 Erlotinib versus chemotherapy as first-line treatment for epidermal growth factor receptor-mutant patients

\begin{tabular}{|c|c|c|c|c|c|c|c|}
\hline Study & $\begin{array}{l}\text { Study } \\
\text { phase }\end{array}$ & $\begin{array}{l}\text { Treatment (number } \\
\text { of patients) }\end{array}$ & ORR (\%) & $\begin{array}{l}\text { Median PFS } \\
\text { (months) }\end{array}$ & HR PFS & $\begin{array}{l}\text { Median OS } \\
\text { (months) }\end{array}$ & HR OS \\
\hline \multirow[t]{3}{*}{ IPASS } & Phase III & Gefitinib (132) & 71.2 & 9.5 & HR 0.48 & 21.6 & HR I.0, \\
\hline & & Carbo + Pac (129) & 47.3 & 6.3 & $P<0.00$ I & 21.9 & $P=0.99$ \\
\hline & & & $P<0.00$ I & & & & \\
\hline \multirow[t]{3}{*}{ OPTIMAL } & Phase III & Erlotinib (82) & 83 & 13.1 & HR 0.16 & 28.85 & HR I.04, \\
\hline & & Carbo + Gem (72) & 36 & 4.6 & $P<0.000$ I & 22.68 & $P=0.69$ \\
\hline & & & $P<0.000$ I & & & & \\
\hline \multirow[t]{3}{*}{ EURTAC } & Phase III & Erlotinib & 58 & 9.7 & HR 0.34 & 22.9 & HR I.36, \\
\hline & & Carbo/Cis + Doc/Gem & 15 & 5.2 & $P<0.0001$ & 18.8 & $P=0.7 \mid$ \\
\hline & & & $P<0.000$ I & & & & \\
\hline
\end{tabular}

Abbreviations: PFS, progression-free survival; ORR, objective response rate; OS, overall survival; Cis, cisplatin; Carbo, carboplatin; Pac, paclitaxel; Doc, docetaxel; Gem, gemcitabine; HR, hazard ratio; IPASS, Iressa Pan-Asia Study; EURTAC, EURopean TArceva vs Chemotherapy.

platinum-based chemotherapy as first-line treatment, erlotinib significantly extended PFS in the EGFR-mutant patients (9.7 versus 5.2 months, HR $0.37,95 \%$ CI $0.25-0.54$; $P<0.0001) .{ }^{11} \mathrm{RR}$ was also higher in the erlotinib group (58\% versus $15 \%)$. Main grade 3 or 4 toxicities were rash (13\% given erlotinib versus none in the chemotherapy group), neutropenia (none versus $22 \%$ ), anemia ( $1 \%$ versus $4 \%$ ), and increased aminotransferase concentrations ( $2 \%$ versus 0$)$. Five $(6 \%)$ patients on erlotinib had treatment-related severe AEs compared with 16 patients $(20 \%)$ on chemotherapy.

Based on the encouraging results of these randomized Phase III studies, which confirmed the role of first-line erlotinib in patients with activating EGFR mutations, erlotinib has been approved to be used as standard first-line treatment in EGFR mutation-positive NSCLC patients.

However, notably, OS benefit was not observed in these studies (median OS, OPTIMAL erlotinib versus GC, HR 1.065, $P=0.6849$; EUARTAC erlotinib versus platinum-based chemotherapy, HR 1.36, $P=0.71$ ). This could be explained by the crossover of treatments after progression. The released survival analysis revealed that median OS of patients exposed to both chemotherapy and erlotinib (in any line of treatment) was 30.4 months compared with 20.7 months in patients exposed to erlotinib only, and 11.7 months in patients exposed to chemotherapy only. Thus, for patients with activating EGFR mutations, it may be an optimal strategy to receive both chemotherapy and erlotinib treatment, regardless of the order of use. However, to date, there has been no robust evidence to show significant differences in PFS and OS between patients receiving first-line erlotinib and those receiving second-line erlotinib. Therefore, should erlotinib be used in early treatment or later is still a problem to solve. For this reason, a Phase III clinical trial (ENSURE [A Study of Tarceva \{Erlotinib\} Versus Gemcitabine/Cisplatin as First-Line Treatment in Patients with Non-Small Cell Lung Cancer with EGFR Mutations]; NCT01342965) $)^{31}$ in the PRC is under way to compare the benefit of first-line versus second-line erlotinib treatment in patients with activating EGFR mutations. In this trial, patients were randomized to receive either erlotinib or 3-week cycles of a GC regimen until disease progression or unacceptable toxicity occurs (or up to four cycles of combined chemotherapy), and then two groups were crossed over to the opposite treatment. Further mature data is needed to evaluate this issue.

\section{Sequential intercalated combination regimens of chemotherapy and erlotinib}

It is important to note that activating EGFR mutations were found in only $30 \%-40 \%$ of Chinese patients with adenocarcinoma, not to mention that the take-up rate of $E G F R$-mutation testing was only $10 \%$, which means that $E G F R$-mutation status might still be unknown in most patients at the time when decisions are made regarding their first-line treatments. ${ }^{32}$ For these patients, a combination of chemotherapy and EGFR TKIs might be an optimal option. Even though previous Phase III studies in unselected populations showed that a combination of chemotherapy and erlotinib did not improve survival compared with chemotherapy alone, ${ }^{26,27}$ sequential intercalated combination regimens of chemotherapy and erlotinib (FASTACT [First-line Asian Sequential Tarceva And Chemotherapy Trial]) have been shown to induce significant improvement in responses and PFS, especially in patients with adenocarcinoma. ${ }^{33}$

To confirm this finding, FASTACT-2 was launched by $\mathrm{Wu}$ et al in the PRC and other Asian countries. ${ }^{34}$ In this Phase III trial, patients with untreated stage IIIB/IV NSCLC were randomly assigned in a 1:1 ratio to receive six cycles of gemcitabine plus platinum with intercalated erlotinib $(150 \mathrm{mg} /$ day on days 15-28, orally; chemotherapy plus erlotinib) or placebo orally (chemotherapy plus placebo) every 4 weeks. Patients continued to receive erlotinib or placebo until progression, unacceptable toxicity, or death, and all patients 
in the placebo group were offered second-line erlotinib at the time of progression. A total of 451 patients were randomly assigned to chemotherapy plus erlotinib $(n=226)$ or chemotherapy plus placebo $(n=225)$. PFS was significantly prolonged with chemotherapy plus erlotinib versus chemotherapy plus placebo (median PFS 7.6 months versus 6.0 months, HR $0.57 ; P<0.0001)$. Median OS for patients in the chemotherapy-plus-erlotinib and chemotherapy-plus-placebo groups was 18.3 months and 15.2 months, respectively (HR $0.79, P=0.0420$ ). A statistically significant treatment benefit was observed in patients with an activating EGFR gene mutation (median PFS 16.8 months versus 6.9 months, HR 0.25, $P<0.0001$; median OS 31.4 months versus 20.6 months, HR 0.48, $P=0.0092$ ). Although no significant difference was observed in either median PFS or OS in patients with $E G F R$ wild-type disease in the chemotherapy-plus-erlotinib group versus those in the chemotherapy-plus-placebo group, median PFS (7.1 months versus 6.0 months, HR 0.61; $P=0.0009)$ significantly improved in patients with unknown $E G F R$-mutation status, revealing that the intercalated combination of chemotherapy and EGFR TKIs could be a reasonable treatment option for patients with an unknown mutation status in whom clinical parameters are suggestive of a high incidence of EGFR mutations.

\section{Maintenance therapy}

Maintenance therapy, which is defined as "any treatment that is given to keep cancer from progressing after it has been successfully controlled by the appropriate first-line therapy", has become an established paradigm in advanced NSCLC treatment. ${ }^{35}$ The rationale for this strategy is that continuous treatment could effectively delay disease progression and improve survival. Nowadays, various agents have been applied in maintenance regimens, such as bevacizumab, ${ }^{36,37}$ cetuximab, ${ }^{38,39}$ docetaxel, ${ }^{40}$ gemcitabine, ${ }^{41}$ and pemetrexed, ${ }^{42,43}$ for switching or continuous maintenance therapy. However, of interest, the most robust results were observed in clinical trials that evaluated EGFR TKIs (erlotinib or gefitinib) as switch maintenance agents (Table 3).

SATURN (2010, Sequential Tarceva in UnResectable NSCLC), a Phase III study of erlotinib as maintenance treatment in patients with nonprogressive disease after first-line chemotherapy, confirmed the efficacy and safety of erlotinib in this setting. ${ }^{44} \mathrm{~A}$ total of 1,949 patients received at least one dose of standard doublet chemotherapy in the run-in phase prior to randomization, of whom 889 patients had complete/ partial response or stable disease after four cycles of standard chemotherapy and were randomized to receive erlotinib or placebo. Median PFS and OS were significantly longer with erlotinib than with placebo (median PFS 12.3 weeks versus 11.1 weeks, HR 0.71, $P<0.0001$; median OS 12.0 versus 11.0 months, HR 0.81, $P=0.0088$ ). Biomarker analysis showed that there was no significant interaction for EGFR protein expression or EGFR copy number, but patients with EGFR-activating mutations in exons 19 or 21 derived significantly greater PFS benefit from maintenance erlotinib (HR $0.10, P<0.0001)$ compared with those with wild-type tumors (HR 0.780, $P=0.018$; treatment-by-mutation interaction, $P<0.001)$. However, EGFR mutation status did not predict for an OS benefit. The later INFORM (Gefitinib as maintenance therapy in patients with locally advanced or metastatic non-small cell lung cancer) study (2011, CTONG 0804) in the PRC further supported the important role of EGFR TKIs (gefitinib) in maintenance therapy for NSCLC. ${ }^{45}$

Subsequently, a retrospective subanalysis of efficacy and safety in Asian patients enrolled in the SATURN study was performed, since Asian patients were reported to gain more benefit from EGFR TKIs compared with non-Asian patients. ${ }^{15}$ In the initial phase, 241 patients were enrolled from the E/SE Asian region, including 46 from the PRC. Of these patients, 125 (including 28 from the PRC) were randomized to receive either erlotinib $(n=60)$ or placebo $(n=65)$. Erlotinib-maintenance therapy significantly prolonged PFS compared with placebo in the overall Asian subpopulation

Table 3 Erlotinib versus placebo as maintenance therapy

\begin{tabular}{|c|c|c|c|c|c|c|c|c|}
\hline Study & $\begin{array}{l}\text { Study } \\
\text { phase }\end{array}$ & $\begin{array}{l}\text { Frontline } \\
\text { therapy }\end{array}$ & $\begin{array}{l}\text { Maintenance } \\
\text { therapy }\end{array}$ & Population & $\begin{array}{l}\text { Median } \\
\text { PFS/TTP }\end{array}$ & $\begin{array}{l}\text { HR PFS/ } \\
\text { TTP }\end{array}$ & $\begin{array}{l}\text { Median OS } \\
\text { (months) }\end{array}$ & HR OS \\
\hline \multirow[t]{4}{*}{ SATURN } & Phase III & Platinum-based & Erlotinib & Overall ITT & 12.3 weeks & HR 0.7I & 12.0 & HR 0.8I, \\
\hline & & doublets & Placebo & & II.I weeks & $P<0.000$ I & 11.0 & $P=0.0088$ \\
\hline & & & & Asian & I 7.9 weeks & HR 0.57 & 20.8 & HR 0.67, \\
\hline & & & & & I I.4 weeks & $P=0.0067$ & 15.2 & $P=0.0931$ \\
\hline \multirow[t]{2}{*}{ INFORM } & Phase III & Platinum-based & Gefitinib & Chinese & 4.8 months & HR 0.42 & 18.7 & HR 0.84 \\
\hline & & doublets & Placebo & & 2.6 months & $P<0.0001$ & 16.9 & $P=0.26$ \\
\hline
\end{tabular}

Abbreviations: PFS, progression-free survival; ORR, objective response rate; OS, overall survival; HR, hazard ratio; ITT, intention to treat; SATURN, Sequential Tarceva in Unresectable NSCLC [non-small-cell lung cancer]; TTP, time to progression; INFORM, Gefitinib as maintenance therapy in patients with locally advanced or metastatic non-small cell lung cancer. 
(HR 0.57, $P=0.0067$ ) and also in the subgroup of Asian patients with EGFR immunohistochemistry (IHC)-positive status (HR 0.50, $P=0.0057$ ). There was a nonsignificant trend towards increased OS in the erlotinib treatment arm in the Asian subpopulation (HR 0.67, $P=0.0931$ ), which reached statistical significance in Asian patients with EGFR IHC-positive status (HR 0.53, $P=0.0233$ ). TTP was also significantly prolonged in the erlotinib arm versus the placebo arm in the Asian subpopulation (HR 0.54, $P=0.0038$ ). Furthermore, erlotinib treatment produced a significantly higher ORR compared with placebo $(23.7 \%$ versus $4.8 \%$, $P=0.0025)$. These data showed that the survival benefits of erlotinib-maintenance therapy in the Asian subpopulation were consistent with those in the global SATURN population, for both the intention-to-treat population and the EGFR IHC-positive Asian subgroup. Meanwhile, erlotinib was generally well tolerated in Asian patients and did not impair quality of life compared with placebo. Thus, erlotinibmaintenance treatment provides a treatment option in Asian patients with advanced NSCLC who have not progressed after first-line chemotherapy. Unfortunately, the data are inherently less robust than those of the SATURN intention-totreat population, due to the retrospective nature of the analysis. Moreover, the researchers were unable to evaluate efficacy outcomes by EGFR-mutation status, because of a lack of sample material for gene analysis in the Asian population.

\section{Adjuvant and neoadjuvant therapy for early stage and locally advanced NSCLC}

So far, there has been no sufficient evidence for EGFR TKIs to be used either as adjuvant or as neoadjuvant treatment in patients with early and locally advanced NSCLC. Surgery and radiation (with or without chemotherapy) are still the standard treatments for these patients.

There is no obvious role for EGFR TKIs as postoperative treatment in patients with stage II and IIIA disease. The National Cancer Institute of Canada BR.19 trial, which was designed to investigate the efficacy and tolerability of gefitinib in patients with completely resected NSCLC, showed that gefitinib did not improve disease-free survival or OS, even in 15 patients with $E G F R$ mutation-positive tumors. ${ }^{46}$ Different from the BR.19 trial, in another ongoing study - RADIANT (Randomized Double-blind Trial in Adjuvant NSCLC with Tarceva) - a large randomized trial of postoperative adjuvant erlotinib versus placebo, $E G F R$ and $K R A S$ mutations, circulating deoxyribonucleic acid, EGFR ligands, and other potential markers will be studied to investigate further the predictive values of these biomarkers for adjuvant therapy of erlotinib. ${ }^{47}$

Since patients harboring EGFR-activating mutations showed excellent response to EGFR TKIs in advanced settings, several studies were initiated to explore the role of EGFR TKIs in the adjuvant setting in selected subgroup of patients in the PRC. A randomized Phase III trial (CTONG 1104, NCT01405079) ${ }^{48}$ was conducted to compare gefitinib with adjuvant vinorelbine plus cisplatin in patients with surgically resected EGFR mutation-positive adenocarcinoma. Another Phase II clinical trial (ML28280, NCT01410214) ${ }^{49}$ is underway to assess the efficacy and safety of erlotinib versus adjuvant vinorelbine plus cisplatin as adjuvant treatment in patients with stage IIIA NSCLC after complete resection with $E G F R$-activating mutations.

In addition, for patients with stage IIIA NSCLC, although concurrent chemoradiation therapy remains a recommended treatment, the optimal treatment paradigm is still not clearly defined. The efficacy and safety of erlotinib as neoadjuvant treatment in patients with stage IIIA-N2 NSCLC with EGFR-activating mutations is also being investigated. A Phase II study (NCT00600587), ${ }^{50}$ which evaluated the value of induction-erlotinib therapy before thoracotomy or radiotherapy in IIIA-N2 (confirmed by mediastinoscopy or positron emission tomography) NSCLC selected by EGFR gene analysis, has just finished enrollment and the results are to be published. The ongoing Erlotinib Versus Gemcitabine/Cisplatin as (Neo)Adjuvant Treatment in non-Small Cell Lung Cancer (EMERGING; CTONG1103, NCT01407822) $)^{51}$ study and another Phase II study (ML25444, NCT01217619) ${ }^{52}$ are trying to evaluate the efficacy and safety of erlotinib as (neo)adjuvant treatment in patients with stage IIIA-N2 NSCLC with activating EGFR mutations. These studies may provide encouraging evidence in the application of EGFR TKIs in adjuvant and neoadjuvant treatment in patients with early and locally advanced NSCLC in the near future.

\section{Acquired resistance}

Even though the initial response to erlotinib was dramatic, the majority of patients with $E G F R$-sensitive mutations suffered disease progression after a median of 10-14 months due to acquired resistance..$^{10,20,28}$ In view of the sometimes-indolent nature of EGFR TKI-resistant tumors and the disease flare after withdrawal of EGFR TKIs, several strategies have been developed to overcome acquired resistance, including switching to cytotoxic therapies ${ }^{53}$ or irreversible EGFR inhibitors ${ }^{54,55}$ in combination with other signal inhibitors, ${ }^{56,57}$ 
local therapy, or cytotoxic therapies. ${ }^{58}$ But the best treatment mode remains unclear.

To date, clinically, the tumor burden and performance status of patients have been the basis for our therapeutic decisions. In a previous study, the progression pattern was divided into three clinical modes to describe the diversity of EGFR TKI resistance: dramatic progression, gradual progression, and local progression. ${ }^{59}$ The difference in PFS and OS among the three groups was significant $(P=0.007)$. Further analysis showed that continuous EGFR TKI treatment was superior to switching to chemotherapy in the gradual-progression cohort (OS 39.4 months versus 17.8 months, $P=0.02$ ), while patients in the dramatic-progression group demonstrated better survival with switching to chemotherapeutic regimens. However, despite the clinical features, it is still unclear if there is a biomarker that could effectively guide the choice of subsequent treatment after acquired resistance to EGFR TKIs. A few clinical trials are ongoing to investigate treatment strategies after EGFR TKI failure, including ASPIRATION (Phase II Study of Continued Erlotinib Beyond RECIST Progression in Asian Patients (Pts) with Epidermal Growth Factor Receptor [EGFR] Mutation-Positive non-Small Cell Lung Cancer [NSCLC] $)^{60}$ and IMPRESS (A Study of IRESSA Treatment Beyond Progression in Addition to Chemotherapy Versus Chemotherapy Alone; NCT01544179) ${ }^{61}$. More importantly, deeper molecular characterization of the primary tumor or metastases by rebiopsy should be recommended to explore further the optimal treatment strategy when patients obtain acquired resistance. ${ }^{62}$

\section{Conclusion}

In the beginning, erlotinib was considered to be used in combination with chemotherapy as the first-line treatment of advanced NSCLC, but it was proved to be ineffective. ${ }^{26,27}$ This could be explained by the hypothesis that a negative interaction occurs between EGFR TKIs and cytotoxic agents when they are given concurrently, and that there are no molecular biomarkers to identify appropriate patients. Subsequently, several randomized studies have demonstrated the promising efficacy of erlotinib in second-line or third-line for patients with advanced NSCLC, including the BR.21 and TRUST studies. ${ }^{89}$ Interestingly, further subgroup analysis revealed that the efficacy and safety outcomes of erlotinib in the Asian population were better than those observed in the non-Asian population. ${ }^{23}$ Unsurprisingly, in Chinese patients, significant survival benefit from erlotinib was also observed. ${ }^{14}$ The benefit was likely to be driven by the presence of high rates of $E G F R$ mutations. However, so far, there appears to be insufficient evidence to suggest that Chinese patients with EGFR mutations benefit any more or less from EGFR TKI therapy than patients from other ethnicities with the same EGFR mutation.

On the basis of results from the OPTIMAL and EURTAC studies, erlotinib has been approved as standard first-line treatment for patients with activating EGFR mutations. ${ }^{10,11}$ The FASTACT-2 study was the first to report significant prolongation of OS in patients with activating EGFR-mutation NSCLC, which provided a new treatment mode. ${ }^{34}$ Nevertheless, more evidence is needed to determine the timing of EGFR TKI administration for a better survival outcome.

Maintenance therapy with erlotinib was shown to improve PFS and OS in the SATURN study. ${ }^{44}$ As a result, erlotinib monotherapy has been approved for patients with advanced NSCLC with nonprogressive disease after first-line platinumbased initial chemotherapy. Still, it is not clear whether all patients with nonprogressive disease should receive maintenance therapy, especially those with activating EGFR mutations, for the effect of erlotinib on OS did not reach statistical significance in these patients compared to patients with wild-type $E G F R$.

At present, there is no precise role for erlotinib in early stage and locally advanced-stage NSCLC in patients with $E G F R$ mutations or in those with EGFR wild-type tumors. Additional well-designed randomized controlled trials are needed to explore the efficacy and safety of erlotinib in adjuvant and neoadjuvant settings.

In conclusion, treatment with erlotinib as first-line, second-line, subsequent and maintenance therapy could significantly delay disease progression and be well tolerated in patients harboring activating EGFR mutations. $E G F R$-mutation status is the strongest predictive biomarker for the efficacy of erlotinib treatment, and is more common in the Asian (including Chinese) population. Acquired resistance remains the restriction of durable long-term outcomes of erlotinib. Further efforts are needed to explore new strategies to improve the efficacy of erlotinib treatment in all settings and overcome the drug resistance as well.

\section{Disclosure}

The authors report no conflicts of interest in this work.

\section{References}

1. Hao J, Zhao P, Chen W. [Chinese Cancer Registry Annual Report 2012]. Beijing: Military Medical Science Press; 2013. Chinese

2. Jemal A, Bray F, Center MM, Ferlay J, Ward E, Forman D. Global cancer statistics. CA Cancer J Clin. 2011;61(2):69-90.

3. She J, Yang P, Hong Q, Bai C. Lung cancer in China: challenges and interventions. Chest. 2013;143(4):1117-1126. 
4. Yang P, Allen MS, Aubry MC, et al. Clinical features of 5,628 primary lung cancer patients: experience at Mayo Clinic from 1997 to 2003. Chest. 2005;128(1):452-462.

5. Rinaldi M, Cauchi C, Gridelli C. First line chemotherapy in advanced or metastatic NSCLC. Ann Oncol. 2006;17 Suppl 5:v64-v67.

6. Schiller JH, Harrington D, Belani CP, et al. Comparison of four chemotherapy regimens for advanced non-small-cell lung cancer. N Engl J Med. 2002;346(2):92-98.

7. Normanno N, Bianco C, De Luca A, Maiello MR, Salomon DS. Target-based agents against ErbB receptors and their ligands: a novel approach to cancer treatment. Endocr Relat Cancer. 2003;10(1): $1-21$.

8. Shepherd FA, Rodrigues Pereira J, Ciuleanu T, et al. Erlotinib in previously treated non-small-cell lung cancer. N Engl J Med. 2005;353(2): 123-132.

9. Reck M, van Zandwijk N, Gridelli C, et al. Erlotinib in advanced nonsmall cell lung cancer: efficacy and safety findings of the global phase IV Tarceva Lung Cancer Survival Treatment study. J Thorac Oncol. 2010;5(10):1616-1622.

10. Zhou C, Wu YL, Chen G, et al. Erlotinib versus chemotherapy as first-line treatment for patients with advanced EGFR mutationpositive non-small-cell lung cancer (OPTIMAL, CTONG-0802): a multicentre, open-label, randomised, phase 3 study. Lancet Oncol. 2011;12(8):735-742.

11. Rosell R, Carcereny E, Gervais R, et al. Erlotinib versus standard chemotherapy as first-line treatment for European patients with advanced EGFR mutation-positive non-small-cell lung cancer (EURTAC): a multicentre, open-label, randomised phase 3 trial. Lancet Oncol. 2012;13(3):239-246.

12. Wu YL, Lee JS, Thongprasert S, et al. Intercalated combination of chemotherapy and erlotinib for patients with advanced stage non-smallcell lung cancer (FASTACT-2): a randomised, double-blind trial. Lancet Oncol. 2013;14(8):777-786.

13. Cappuzzo F, Ciuleanu T, Stelmakh L, et al. Erlotinib as maintenance treatment in advanced non-small-cell lung cancer: a multicentre, randomised, placebo-controlled phase 3 study. Lancet Oncol. 2010;11(6): 521-529.

14. Wu YL, Liao ML, Qin SK, Sun Y, Zhou CC. [Efficacy and safety of erlotinib in the treatment for advanced non-small cell lung cancer in Chinese patients]. Zhonghua Zhong Liu Za Zhi. 2010;32(2):148-151. Chinese.

15. Wu YL, Kim JH, Park K, Zaatar A, Klingelschmitt G, Ng C. Efficacy and safety of maintenance erlotinib in Asian patients with advanced non-small-cell lung cancer: a subanalysis of the phase III, randomized SATURN study. Lung Cancer. 2012;77(2):339-345.

16. Paez JG, Janne PA, Lee JC, et al. EGFR mutations in lung cancer: correlation with clinical response to gefitinib therapy. Science. 2004;304(5676):1497-1500.

17. Lynch TJ, Bell DW, Sordella R, et al. Activating mutations in the epidermal growth factor receptor underlying responsiveness of nonsmall-cell lung cancer to gefitinib. $N$ Engl J Med. 2004;350(21): 2129-2139.

18. Mok T, Lui P, Lam K, et al. Novel mutations and mutation pattern of epidermal growth factor receptor (EGFR) gene in Chinese patients with primary lung adenocarcinoma. J Clin Oncol. 2007; 25(18 Suppl 7667):426s.

19. Kosaka T, Yatabe Y, Onozato R, et al. Prognostic implication of the EGFR gene mutations in a large cohort of Japanese patients with early prognostic implication of the EGFR gene mutations in a large cohort of Japanese patients with early stage lung adenocarcinoma. J Clin Oncol. 2007;25(18 Suppl):7574.

20. Rosell R, Moran T, Queralt C, et al. Screening for epidermal growth factor receptor mutations in lung cancer. N Engl J Med. 2009;361(10): 958-967.

21. An SJ, Chen $\mathrm{ZH}, \mathrm{Su}$ J, et al. Identification of enriched driver gene alterations in subgroups of non-small cell lung cancer patients based on histology and smoking status. PLoS One. 2012;7(6):e40109.
22. Heigener DF, Wu YL, van Zandwijk N, Mali P, Horwood K, Reck M. Second-line erlotinib in patients with advanced non-small-cell lung cancer: subgroup analyses from the TRUST study. Lung Cancer. 2011;74(2):274-279.

23. Mok T, Wu YL, Au JS, et al. Efficacy and safety of erlotinib in 1242 East/South-East Asian patients with advanced non-small cell lung cancer. J Thorac Oncol. 2010;5(10):1609-1615.

24. Yoshio O, Masahiko A, Kazuhiro A. Randomized phase III trial of erlotinib (E) versus docetaxel (D) as second- or third-line therapy in patients with advanced non-small cell lung cancer (NSCLC) who have wild-type or mutant epidermal growth factor receptor (EGFR): Docetaxel and Erlotinib Lung Cancer Trial (DELTA). J Clin Oncol. 2013(Suppl 31):8006.

25. Yang JJ, Cheng Y, Zhao MF, et al. A phase II trial comparing pemetrexed with gefitinib as the second-line treatment of nonsquamous NSCLC patients with wild-type EGFR (CTONG0806). J Clin Oncol. 2013(Suppl 31):8042.

26. Herbst RS, Prager D, Hermann R, et al. TRIBUTE: a phase III trial of erlotinib hydrochloride (OSI-774) combined with carboplatin and paclitaxel chemotherapy in advanced non-small-cell lung cancer. J Clin Oncol. 2005;23(25):5892-5899.

27. Gatzemeier U, Pluzanska A, Szczesna A, et al. Phase III study of erlotinib in combination with cisplatin and gemcitabine in advanced non-small-cell lung cancer: the Tarceva Lung Cancer Investigation Trial. J Clin Oncol. 2007;25(12):1545-1552.

28. MokTS, Wu YL, Thongprasert S, et al. Gefitinib or carboplatin-paclitaxel in pulmonary adenocarcinoma. $N$ Engl J Med. 2009;361(10): 947-957.

29. Maemondo M, Inoue A, Kobayashi K, et al. Gefitinib or chemotherapy for non-small-cell lung cancer with mutated EGFR. $N$ Engl J Med. 2010;362(25):2380-2388.

30. Mitsudomi T, Morita S, Yatabe Y, et al. Gefitinib versus cisplatin plus docetaxel in patients with non-small-cell lung cancer harbouring mutations of the epidermal growth factor receptor (WJTOG3405): an open label, randomised phase 3 trial. Lancet Oncol. 2010;11(2):121-128.

31. Hoffmann-La Roche. A Study of Tarceva (Erlotinib) Versus Gemcitabine/Cisplatin as First-Line Treatment in Patients With Non-Small Cell Lung Cancer With EGFR Mutations. In: ClinicalTrials.gov [website on the Internet]. Bethesda, MD: US National Library of Medicine; 2011 [updated January 20, 2014]. Available from: http://clinicaltrials. gov/show/NCT01342965. NLM identifier: NCT01342965. Accessed January 24, 2014.

32. Xue $\mathrm{C}, \mathrm{Hu} \mathrm{Z}$, Jiang W, et al. National survey of the medical treatment status for non-small cell lung cancer (NSCLC) in China. Lung Cancer. 2012;77(2):371-375

33. Mok TS, Wu YL, Yu CJ, et al. Randomized, placebo-controlled, phase II study of sequential erlotinib and chemotherapy as first-line treatment for advanced non-small-cell lung cancer. J Clin Oncol. 2009;27(30): 5080-5087.

34. Wu YL, Lee JS, Thongprasert S, et al. Intercalated combination of chemotherapy and erlotinib for patients with advanced stage non-smallcell lung cancer (FASTACT-2): a randomised, double-blind trial. Lancet Oncol. 2013;14(8):777-786.

35. Gridelli C, Maione P, Rossi A, et al. Potential treatment options after first-line chemotherapy for advanced NSCLC: maintenance treatment or early second-line? Oncologist. 2009;14(2):137-147.

36. Reck M, von Pawel J, Zatloukal P, et al. Phase III trial of cisplatin plus gemcitabine with either placebo or bevacizumab as first-line therapy for nonsquamous non-small-cell lung cancer: AVAil. J Clin Oncol. 2009;27(8):1227-1234.

37. Sandler A, Gray R, Perry MC, et al. Paclitaxel-carboplatin alone or with bevacizumab for non-small-cell lung cancer. $N$ Engl J Med. 2006;355(24):2542-2550

38. Belani CP, Schreeder MT, Steis RG, et al. Cetuximab in combination with carboplatin and docetaxel for patients with metastatic or advancedstage nonsmall cell lung cancer: a multicenter phase 2 study. Cancer. 2008;113(9):2512-2517. 
39. Pirker R, Pereira JR, Szczesna A, et al. Cetuximab plus chemotherapy in patients with advanced non-small-cell lung cancer (FLEX): an openlabel randomised phase III trial. Lancet. 2009;373(9674):1525-1531.

40. Fidias PM, Dakhil SR, Lyss AP, et al. Phase III study of immediate compared with delayed docetaxel after front-line therapy with gemcitabine plus carboplatin in advanced non-small-cell lung cancer. J Clin Oncol. 2009;27(4):591-598.

41. Brodowicz T, Krzakowski M, Zwitter M, et al. Cisplatin and gemcitabine first-line chemotherapy followed by maintenance gemcitabine or best supportive care in advanced non-small cell lung cancer: a phase III trial. Lung Cancer. 2006;52(2):155-163.

42. Ciuleanu T, Brodowicz T, Zielinski C, et al. Maintenance pemetrexed plus best supportive care versus placebo plus best supportive care for non-small-cell lung cancer: a randomised, double-blind, phase 3 study. Lancet. 2009;374(9699):1432-1440.

43. Paz-Ares L, de Marinis F, Dediu M, et al. Maintenance therapy with pemetrexed plus best supportive care versus placebo plus best supportive care after induction therapy with pemetrexed plus cisplatin for advanced non-squamous non-small-cell lung cancer (PARAMOUNT): a double-blind, phase 3, randomised controlled trial. Lancet Oncol. 2012;13(3):247-255

44. Cappuzzo F, Ciuleanu T, Stelmakh L, et al. Erlotinib as maintenance treatment in advanced non-small-cell lung cancer: a multicentre, randomised, placebo-controlled phase 3 study. Lancet Oncol. 2010;11(6): 521-529.

45. Zhang L, Ma S, Song X, et al. Gefitinib versus placebo as maintenance therapy in patients with locally advanced or metastatic non-small-cell lung cancer (INFORM; C-TONG 0804): a multicentre, double-blind randomised phase 3 trial. Lancet Oncol. 2012;13(5):466-475.

46. Goss GD, O'Callaghan C, Lorimer I, et al. Gefitinib versus placebo in completely resected non-small-cell lung cancer: results of the NCIC CTG BR19 study. J Clin Oncol. 2013;31(27):3320-3326.

47. Richardson F, Richardson K, Sennello G, et al. Biomarker analysis from completely resected NSCLC patients enrolled in an adjuvant erlotinib clinical trial (RADIANT). J Clin Oncol. 2009;27 Suppl:7520.

48. Guangdong Association of Clinical Trials. Gefitinib Versus Vinorelbine/ Platinum as Adjuvant Treatment in Stage II-IIIA(N1-N2) NSCLC With EGFR Mutation (ADJUVANT). In: ClinicalTrials.gov [website on the Internet]. Bethesda, MD: US National Library of Medicine; 2011 [updated September 5, 2013]. Available from: http://clinicaltrials. gov/ct2/show/NCT01405079?term=NCT01405079\&rank=1. NLM identifier: NCT01405079. Accessed January 24, 2014.

49. Chinese Lung Cancer Surgical Group. Erlotinib Versus Vinorelbine/ Cisplatin as Adjuvant Treatment in Stage IIIA NSCLC Patients With EGFR Mutations. In: ClinicalTrials.gov [website on the Internet]. Bethesda, MD: US National Library of Medicine; 2011 [updated December 21, 2011]. Available from: http://clinicaltrials.gov/ct2/ show/NCT01410214?term=NCT01410214\&rank=1. NLM identifier: NCT01410214. Accessed January 24, 2014.

50. Guangdong Provincial People's Hospital. Induction Erlotinib Therapy in Stage III A (N2) Non-Small Cell Lung Cancer (NSCLC). In: ClinicalTrials.gov [website on the Internet]. Bethesda, MD: US National Library of Medicine; 2008 [updated June 23, 2013]. Available from: http:// clinicaltrials.gov/ct2/show/NCT00600587?term=NCT00600587\& rank=1. NLM identifier: NCT00600587. Accessed January 24, 2014.
51. Guangdong Association of Clinical Trials. Erlotinib Versus Gemcitabine/Cisplatin as (Neo)Adjuvant Treatment in Non-small Cell Lung Cancer (EMERGING). In: ClinicalTrials.gov [website on the Internet]. Bethesda, MD: US National Library of Medicine; 2011 [updated September 5, 2013]. Available from: http://clinicaltrials.gov/ct2/ show/NCT01407822?term=NCT01407822\&rank=1. NLM identifier: NCT01407822. Accessed January 24, 2014.

52. Baohui Han. Erlotinib as Neoadjuvant Treatment in Patients With Stage III A N2 NSCLC With Activating EGFR Mutation. (ML25444). In: ClinicalTrials.gov [website on the Internet]. Bethesda, MD: US National Library of Medicine; 2010 [updated March 6, 2012]. Available from: http://clinicaltrials.gov/ct2/show/NCT01217619?term= NCT01217619\&rank=1. NLM identifier: NCT01217619. Accessed January 24, 2014.

53. Kuo CH, Lin SM, Lee KY, et al. Subsequent chemotherapy improves survival outcome in advanced non-small-cell lung cancer with acquired tyrosine kinase inhibitor resistance. Clin Lung Cancer. 2010;11(1): 51-56.

54. Engelman JA, Zejnullahu K, Gale CM, et al. PF00299804, an irreversible pan-ERBB inhibitor, is effective in lung cancer models with EGFR and ERBB2 mutations that are resistant to gefitinib. Cancer Res. 2007;67(24):11924-11932.

55. Li D, Ambrogio L, Shimamura T, et al. BIBW2992, an irreversible EGFR/HER2 inhibitor highly effective in preclinical lung cancer models. Oncogene. 2008;27(34):4702-4711.

56. Schiller JH, Akerley WL, Brugger W, et al. Results from ARQ 197-209: a global randomized placebo-controlled phase II clinical trial of erlotinib plus ARQ 197 versus erlotinib plus placebo in previously treated EGFR inhibitor-naive patients with locally advanced or metastatic non-small cell lung cancer (NSCLC). J Clin Oncol. 2010; 28(Suppl 18):LBA7502.

57. Spigel DR, Ervin TJ, Ramlau R, et al. Final efficacy results from OAM4558g, a randomized phase II study evaluating MetMAb or placebo in combination with erlotinib in advanced NSCLC. $J$ Clin Oncol. 2011;29 Suppl:7505.

58. Janne PA, Wang X, Socinski MA, et al. Randomized phase II trial of erlotinib alone or with carboplatin and paclitaxel in patients who were never or light former smokers with advanced lung adenocarcinoma: CALGB 30406 trial. J Clin Oncol. 2012;30(17):2063-2069.

59. Yang JJ, Chen HJ, Yan HH, et al. Clinical modes of EGFR tyrosine kinase inhibitor failure and subsequent management in advanced non-small cell lung cancer. Lung Cancer. 2013;79(1):33-39.

60. Park K, Tsai C, Ahn M, et al. ASPIRATION: Phase II study of continued erlotinib beyond RECIST progression in Asian patients (pts) with epidermal growth factor receptor (EGFR) mutation-positive non-small cell lung cancer (NSCLC). J Clin Oncol. 2012;30 Suppl:TPS7614.

61. AstraZeneca. A Study of IRESSA Treatment Beyond Progression in Addition to Chemotherapy Versus Chemotherapy Alone (IMPRESS). In: ClinicalTrials.gov [website on the Internet]. Bethesda, MD: US National Library of Medicine; 2012 [updated November 7, 2013]. Available from: http:/clinicaltrials.gov/ct2/show/NCT01544179?term= NCT01544179\&rank=1. NLM identifier: NCT01544179. Accessed January 24, 2014.

62. Zhuang HQ, Yuan ZY, Wang J, Wang P, Zhao LJ, Zhang BL. Research progress on criteria for discontinuation of EGFR inhibitor therapy. Onco Targets Ther. 2012;5:263-270.
OncoTargets and Therapy

\section{Publish your work in this journal}

OncoTargets and Therapy is an international, peer-reviewed, open access journal focusing on the pathological basis of all cancers, potential targets for therapy and treatment protocols employed to improve the management of cancer patients. The journal also focuses on the impact of management programs and new therapeutic agents and protocols on

\section{Dovepress}

patient perspectives such as quality of life, adherence and satisfaction The manuscript management system is completely online and includes a very quick and fair peer-review system, which is all easy to use. Visit http://www.dovepress.com/testimonials.php to read real quotes from published authors. 